Nigerian Journal of Environmental Sciences and Technology (NIJEST)

www.nijest.com

ISSN (Print): 2734-259X ｜ＩSSN (electronic): 2734-2603

Vol 5, No. 1March 2021, pp 173 - 190

\title{
Validating Gauge-based Spatial Surface Atmospheric Temperature Datasets for Upper Benue River Basin, Nigeria
}

\author{
Salaudeen A. ${ }^{1,2, *}$, Ismail A. ${ }^{1}$, Adeogun B. K. ${ }^{1}$ and Ajibike M. A. ${ }^{1}$ \\ ${ }^{1}$ Department of Water Resources and Environmental Engineering, Ahmadu Bello University Zaria, Nigeria \\ ${ }^{2}$ Department of Civil Engineering, Abubakar Tafawa Balewa University, Bauchi, Nigeria \\ Corresponding Author: *asalaudeen@ atbu.edu.ng
}

https://doi.org/10.36263/nijest.2021.01.0259

\begin{abstract}
Like most other countries of Africa, one of the main problems threatening effective impact modelling in Nigeria including Upper Benue river basin, dwells in lack of high-quality in-situ observation datasets at appropriate spatiotemporal scales. Gridded meteorological variables can serve as promising alternatives to in-situ measurements in data sparse regions, but then, require validations to assess quantitatively their level of accuracies and reliabilities. As a consequence, this study makes comparative analysis of two gauge-based, spatially interpolated surface atmospheric temperature datasets with in-situ measurements in seven distinct meteorological stations covering the period of 1982-2006. Correspondingly, spatial analysis and statistical measures were used to assess the performances of the gridded datasets from the Climate Research Unit (CRU) and the Climate Prediction Centre $(C P C)$. Results from spatial distributions depict 8 , 11 and $10{ }^{\circ} \mathrm{C}$ as observed minimum temperatures and 33, 36, $42{ }^{\circ} \mathrm{C}$ as observed maximum temperatures over the Cameroon highland (Gembu), the Jos plateau and at the northern fringes of the basin respectively. Consequently, both the CRU and CPC datasets captured remarkably well the observed temperature gradients along the varying topography, though with differing margins. The interannual variabilities indicate CRU dataset to better capture the signs and magnitudes of the observed anomalies as compared to the CPC data. Moreover, the CRU data was noted to be more outstanding in representing the observed features in seasonal temperature variations over most stations. Also, the shapes of the probability density function (PDF) for both datasets in minimum and maximum temperatures measured closely the shapes of the observed PDF. Trend analysis suggests CRU datasets to better represent the warming and the cooling trends than the $C P C$. Overall, the CRU datasets are the most outstanding in this study and is therefore preferred for water resource application over the study area.
\end{abstract}

Keywords: Assessment, Upper Benue river basin, temperature, CRU, CPC

\subsection{Introduction}

The variations of near-surface air temperature are influential on agriculture, hydrology, energy and ecosystems; as it is one of the key elements, which represent the state of the atmosphere (Adeniyi and Dilau, 2015; Chen et al., 2014). Thus, understanding the climate systems of a region and their impacts on the environment depends largely on accurate meteorological observations (Chen et al., 2014; Akinsanola and Ogunjobi, 2014). The significant input from Africa continent to the global climate system is well documented in literatures, yet, ground observation networks are non-existence in most remote areas (Hassan et al., 2020), where they are needed for analysis. Even where they exist, the datasets are usually characterized with gaps, limited and restricted accessibility and inadequate spatiotemporal continuity and distributions (Piyoosh and Ghosh, 2016). This is particularly true for most developing countries. This scenario is more poignant in Upper Benue river basin in the northeast of Nigeria, considering the few number of gauging stations for the entire basin. Nevertheless, advancement in computational technologies in recent decades has aided the availability of climate datasets in digital forms over the entire globe (Daly, 2006), which serve as key input data for computer models, particularly in water resource and environmental managements as well hydroclimatological impact assessments. 
The climate datasets have however, witnessed heavy usage within the scientific community, most especially in data sparse regions. Though, the gridded datasets undergo rigorous quality control checks before interpolations. Anyway, errors in datasets are functions of spatial variability of the gauging stations. Therefore, river basins with insufficient meteorological stations and low spatial variability are prone to large interpolation errors (Tanarhte et al., 2012). This explains the sole reason why there is striking regional difference in the datasets, despite their correspondence in geographical distributions and temporal trends (Chen et al., 2014; Burton et al., 2018; Hassan et al., 2020). It is therefore imperative to validate them against ground reference observations, to ascertain their level of accuracies and reliabilities, to avoid drawing erroneous scientific conclusions and defective decisions, which may arise due to poor quality data.

Minimum and maximum temperatures and rainfall datasets are the most common meteorological variables provided by most of the world's meteorological organizations, owing to their dominant influence on hydrology, meteorology and agrometeorology. In any case, precipitation datasets have remained the most studied meteorological variable in recent literature, with less attentions being paid to validation of the temperature products. Consequently, this study presents the inter-comparison of the near-surface atmospheric temperature datasets (Collins, 2011) developed by the Climate Research Unit (CRU) at the University of East Anglia and the Climate Prediction Centre (CPC)-Global Unified Gauge-based Analysis with in-situ measurements to assess their skills in simulating changes in the present climate systems (Fu et al., 2013).

Of the three available gridded datasets namely, gauge-based observations, reanalysis datasets and satellite estimates; gauge-based observations provide relatively accurate and reliable measurements (Hassan et al., 2020). This premised on the fact that they are products of geospatial interpolation of ground-based measurements (Kanda et al., 2020). This accounts for the sole reason why it has been widely used recently, as the basis for drawing scientific conclusions and management decisions. Although the reanalysis products combine irregular measurements of climate data and models to produce a synthesized estimate with uniform spatial distribution and temporal continuity (Sun et al., 2018). They are however, widely used by scientists, but are considered non-observation data. The satellite estimates are well known for adequate spatiotemporal scales, but contain random errors and non-negligible biases (Kanda et al., 2020; Hassan et al., 2020). The fact that the land surface temperatures are derived from satellite estimates through retrieval algorithms from the measured radiant emitted from earth back into the space (Hooker et al., 2018; Kanda et al., 2020), exacerbates the uncertainties.

Nonetheless, gauge-based temperature datasets have been validated in recent literature to suggest probably the most credible datasets for a particular region. For example, Tang et al. (2010) intercompare a number of temperature datasets over China for 100 years period including CRU. Findings from their study showed CRU to be in good concurrence with the Northern Hemisphere, Chinese and Global series. Tanarhte et al. (2012) evaluated the performances of global and regional precipitation and temperature datasets relative to ground observational data over the Middle East and Mediterranean, and remarked that the global temperature datasets including CRU and CPC have good skills in representing the observed pattern over all the sub-regions. In a similar study over Dehradun, India, Piyoosh and Ghosh (2016) noted good correlation between CRU temperature dataset and in-situ observations for different periods between 1901 and 2012. They further opined that the CRU captured well the trends of the observed pattern both in magnitude and direction. Also, Nashwan et al. (2019) examined the capabilities of three gauge-based observations including, CRU, CPC and Udel in replicating the observed temperature patterns for the purpose of developing high-resolution temperature datasets for the north central part of Egypt, and showed CPC-global to be most outstanding of all. However, Kanda et al. (2020) compared seven gridded climate datasets with ground observations over northwest Himalaya; they found out that interpolated temperature estimates better represent the observed pattern than their corresponding precipitation datasets over the mountainous region. The findings revealed CRU, ERA-I, PGF and Udel to outperform APHRODITE at all zones. Furthermore, Hassan et al. (2020) analysed the annual cycle of three gridded climate products such as; CRU, PGF and CFRS in terms of correlation and errors over Niger Delta region of Nigeria for the common period of 1980-2005. Findings from their study recommended CRU data for hydrological applications over the region owing to its least error and highest degree of correspondence with the ground reference observational data. 
Studies on atmospheric temperature in Upper Benue river basin is very limited despite its importance, but over the larger Nigeria. Abatan et al. (2016) studied the trends in extreme daily temperatures (Tmin and Tmax) for 21 stations distributed over the whole Nigeria. Adebayo and Yahya (2015) assessed trends in mean monthly temperature in Savannah Sugar Plantation. Akinsanola and Ogunjobi (2014) investigated variabilities in temperature and precipitation using records from 25 synoptic stations over the whole country. Eludoyin et al. (2014) studied the changes in thermal conditions over the entire Country through temperature and relative humidity. Weli et al. (2017) carried out statistical analysis on minimum and maximum temperatures in Port Harcourt metropolis. Hassan et al. (2020) inter-compared basic meteorological dataset including minimum and maximum temperatures and precipitation in the Niger Delta with ground observational dataset for water resources management. The whole of these studies focused on trend analysis and variability, except Hassan et al. (2020) who evaluated the performances of the temperature data relative to ground observational dataset. However, the study domain lies in the Niger Delta region. It is therefore clear that despite the potentials of the Upper Benue river basin, studies to evaluate gridded temperature data in the basin does not exists, which create significant research vacuum to be filled. The focus of this study therefore dwells on validating gauge-based spatial interpolated atmospheric temperature dataset including; CRU and CPC-global for the common period of 1982 -2006 over Upper Benue river basin for possible water resource applications.

\subsection{Materials and Methods}

\subsection{The study area}

The Upper Benue river basin lies between the tropical rain forests of the southern Nigeria and the Savannah of the north, comprising of four states in the northeast including; Adamawa, Bauchi, Gombe and Taraba states as shown in Figure 1. Though, the basin cut across some other states, notably; the Jos plateau, Yobe and Borno states. It is one of the twelve River Basin Development Authorities (RBDA), with its administrative headquarters in Yola, Adamawa state; and at the same time the hydrological area 3 (HA-3) out of the eight designated hydrological areas in Nigeria. The basin encompasses an area of approximately $156,546 \mathrm{~km}^{2}$. The Jos plateau, the Cameroon highlands and the Biu plateau, which form the western, the southern and the north-eastern boundaries, greatly influence the basin's micro-climate, owing to its varying topography.

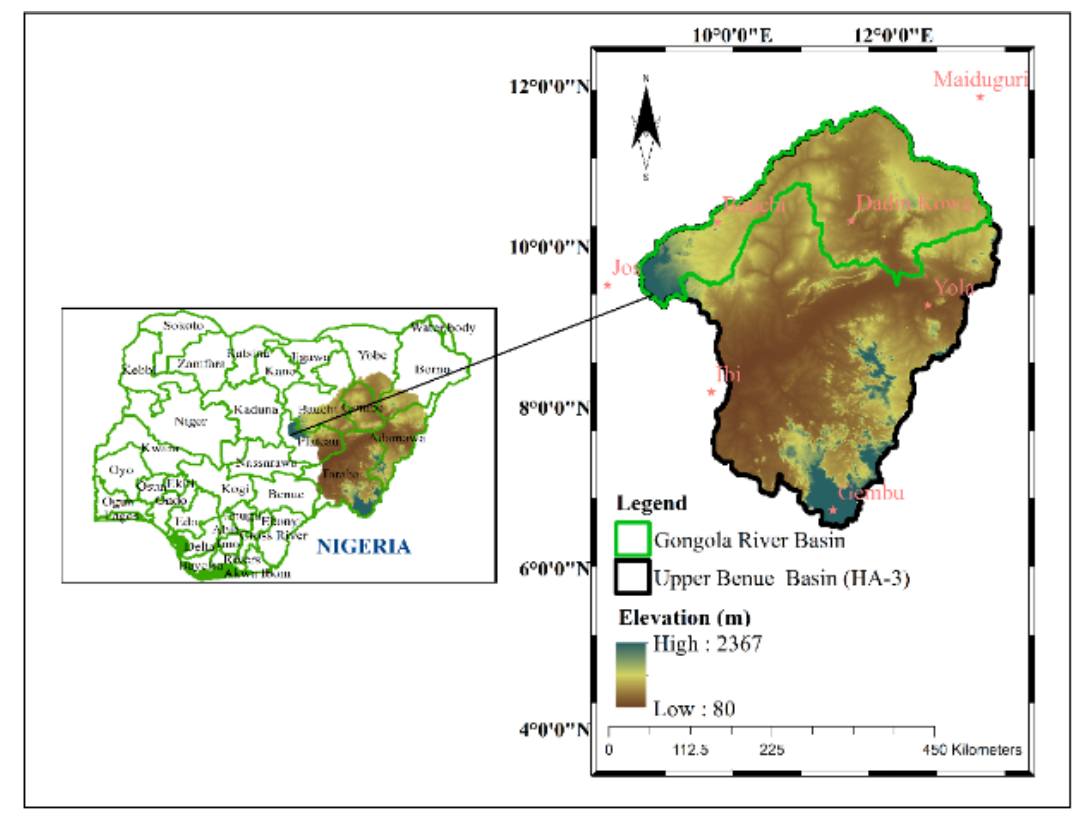

Figure 1: The study area

Three categories of climate are identified with the study area as; the northern Guinea savannah, the Sudan savannah and the montane or highland climates. The northern Guinea savannah extents from the Jos plateau to the southern region of the basin in Taraba state, and over an isolated portion of the Biu plateau. The central and the northern fringes of the basin exhibit Sudan savannah climate. Consequently, the montane climate is experienced over the Cameroun highlands (Eludoyin et al., 
2014), which lies at the southernmost part. Annual rainfall over the basin ranges from $700 \mathrm{~mm}$ to over $1800 \mathrm{~mm}$ (Federal Government of Nigeria, 2012), which contributes over 60.2 billion $\mathrm{m}^{3}$ to the total annual flow of river Benue (Japan International Cooperation Agency (JICA), 2014). Essentially, through the two major river systems; the Gongola, which lies on the right arm of Benue; and the Donga, which is situated on the left arm. These two major tributaries are well known for the annual runoff volumes they contribute to the Benue. They are rated as the largest and the second largest from each arm respectively. The annual temperature of the basin is $26^{\circ} \mathrm{C}$, though it is lower on the plateaus (Federal Government of Nigeria, 2012). The dry season extents from December to March which is usually dry, with prevailing harmattan winds. The dwellers rely mainly on rain-fed agriculture. Thus, agro as well as hydroclimatic studies for the region are crucial for sustainable agriculture and water resource managements. In spite of these potentials, spatiotemporal distribution and continuity of insitu observational datasets is limited; and therefore, appeal for alternative sources of accurate and reliable datasets, which can only be obtained through proper validations.

\subsection{Datasets}

The monthly minimum and maximum near-surface air temperature datasets consisting of seven stations in and around Upper Benue river basin with 24 years records, covering the period of 19822006, were procured from the Nigerian Meteorological Agency (NiMET), Abuja; although, the datasets of Dadin Kowa, Gembu and Yola were obtained from the archive of the Upper Benue River Basin Development Authority (UBRBDA), Yola. These serve as reference observations for the evaluations. The geographical distributions of these stations are sparse and uneven over the basin (Figure 1), owing to the few number of stations maintained by the agency in each state; although, meteorological data are measured by some other organisations e.g. UBRBDA and some higher institutions of learning. However, the datasets are in most cases characterised with gaps, which often render them unsuitable for hydro-climatological impact assessments. Nonetheless, the stations are sited at key locations over the basin, where measurements are most critical.

The Climate Research Unit (CRU TS3.10) datasets were developed at the University of East Anglia, with major contribution from World Meteorological Organization. The data derived its sources mainly from the Global Historical Climatology Network (GHCN-v2), monthly climate bulletin (CLIMAT) (Tanarhte et al., 2012), Monthly Climate Data for the World (MCDW) and World Weather Records (WWR) consisting of over 4000 stations globally (Akinsanola et al., 2016). They consist of gridded climatological variables (Tmin, Tmax and prec) at $0.5^{\circ}$ spatial resolutions at monthly scales covering the entire global land surface from 1901-2014 (Harris et al., 2014; New et al., 2000). However, the daily datasets of the CRU are available globally for the period 1970-2006, downloadable from www.2w2e.com (Vaghefi et al., 2017). The dataset underwent stringent quality control checks through an automated method (New et al., 2000). Anomalies are interpolated rather than the absolute values of the data, which consequently produces high-quality estimates, with fewer biases (New et al., 1999; Tanarhte et al., 2012). In any case, errors in datasets are functions of spatial variability of the gauging station. Incidentally, regions with poor station coverage and high spatial variability are prone to large interpolation errors (Tanarhte et al., 2012), which are noted to be prevalent in cold, dry and mountainous areas. Nonetheless, temperature data produce estimates with better quality than their corresponding precipitation datasets. The summary of the gridded datasets are shown in Table 1.

Table 1: Summary of selected global, spatially interpolated datasets

\begin{tabular}{lccccc}
\hline Dataset \& Source & Product & $\begin{array}{c}\text { Spatial } \\
\text { Resolution }\end{array}$ & $\begin{array}{c}\text { Geographical } \\
\text { Coverage }\end{array}$ & $\begin{array}{c}\text { Temporal } \\
\text { Resolution/Coverage }\end{array}$ & Reference \\
\hline $\begin{array}{l}\text { Climate Research Unit } \\
\text { (CRU) at the }\end{array}$ & CRU TS 3.10 & $0.5^{0} \times 0.5^{0}$ & Global land & Daily (1970-2006) & (Vaghefi et al., 2017) \\
$\begin{array}{l}\text { University of East } \\
\text { Anglia }\end{array}$ & & & & & \\
$\begin{array}{l}\text { Climate Prediction } \\
\begin{array}{l}\text { Centre (CPC)-Global } \\
\text { unified gauge-based } \\
\text { analysis of daily } \\
\text { minimum and maximum } \\
\text { temperature }\end{array}\end{array}$ & CPC-Global & $0.5^{0} \times 0.5^{0}$ & Global land & Daily (1979-Present) & (NOAA/OAR/ESRL PSL) \\
\hline
\end{tabular}


The Climate Prediction Centre gauge-based analysis of global daily minimum and maximum temperature and precipitation product was initiated by the National Oceanic and Atmospheric Administration (NOAA) Climate Prediction Centre. The product is freely available on $0.5^{\circ}$ latitude/longitude grids over the entire global land areas from 1979-present. The mandate is to construct a set of unified climate datasets with improved quality and inter-product consistency to suite a wide range of applications. In formulating the CPC-Global datasets, gauge reports from over 30,000 stations worldwide including Global Telecommunication System (GTS), Cooperative Observer Network (COOP) and other national and international agencies, consisting of in-situ measurements and satellite estimates were utilised (NOAA/OAR/ESRL PSL).

\subsection{Methodology}

The minimum and maximum air temperature climatology of two spatially interpolated datasets including CRU and CPC were evaluated in this study relative to observed meteorological measurements for 24 years period, covering 1982-2006 over the study domain. The study quantifies the degree of pattern correspondence between the gridded datasets and ground reference observations through temporal and geographical distributions and various parametric and nonparametric statistical indices. They include: Probability density function (PDF) overlap, annual long-term temperature anomaly, t', Mann-Kendall test, MK, correlation coefficient, $r$, refined index of agreement $\left(\mathrm{d}_{\text {ref }}\right)$, mean absolute error, MAE, and mean bias error, MBE.

The temporal distributions of the minimum and maximum temperature examine the annual cycle of monthly climatology in all the stations. While, the geographical distributions compare each of the gridded minimum and maximum temperature data over the entire basin with ground observations using spatial description. The PDFs for the gridded observations and in-situ measurements were computed for monthly minimum and maximum temperature in all the seven stations to determine the probability of occurrence of any given data as demonstrated by (Perkins et al., 2007) through MATLAB distribution fitting. The PDF has been widely used by earlier researchers to compare between two climate datasets e.g. Maxino et al. (2008), Anandhi et al. (2019) and Kabela and Carbone (2015). To quantify the area of overlap, which may reveal the degree of correspondence of the two datasets, Perkins et al. (2007) proposed a metric known as Skill Score. This computes the cumulative minimum value of the two distributions of each binned value defined as:

$$
S_{\text {score }}=\sum_{1}^{n} \operatorname{minimum}\left(P_{m}, P_{o}\right)
$$

where $P_{m}$ and $P_{o}$ are the modelled and observed probabilities in a given bin, and $\mathrm{n}$ is the number of bins used in computing the PDF. Consequently, a bin size of $0.5^{\circ}$ was chosen for both the minimum and maximum temperature for these assessments.

A comparison of the spatially interpolated and the ground observation datasets was done through long-term temperature anomaly, defined as:

$$
T_{a}=\frac{T-\bar{T}}{\bar{T}}
$$

where $T$ is the mean annual temperature of a given year and $\bar{T}$ is the long-term average temperature, with positive and negative anomalies indicating warmer and cooler conditions than the baseline period respectively.

Also, Mann-Kendall test [Eq. 3a-3d)] was employed to examine trends in monthly time series of the temperature datasets. This is a nonparametric statistic that has been used in earlier studies for trend analysis in climate time series data due to its robustness (Akinsanola et al., 2017; Abatan et al., 2016; Agyekum et al., 2018; Shiru et al., 2018; Jia et al., 2019; Mondal et al., 2018; Fu et al., 2013; Akande et al., 2017). The method was therefore utilized in this study to assess the trends and the magnitude of monthly time series data at $5 \%$ significant level $(\alpha)$. The test statistic $S_{m}$ is given as: 


$$
S_{m}=\sum_{i=1}^{n-1} \sum_{j=i+1}^{n} \operatorname{sign}\left(x_{j}-x_{i}\right)
$$

where $x$ is the temperature variables and $n$ is the number of observations. If $x_{j}-x_{i}=\varphi$, it then follows that:

$$
\operatorname{sign}(\varphi)=\left\{\begin{array}{cc}
1 & \text { if } \varphi>1 \\
0 & \text { if } \varphi=0 \\
-1 & \text { if } \varphi<1
\end{array}\right.
$$

The standardized $S_{m}$ is computed by equation of the form:

$$
Z_{S m}= \begin{cases}\frac{S_{m}-1}{\sqrt{\operatorname{Var}\left(S_{m}\right)}} & \text { if } S_{m}>1 \\ 0 & \text { if } S_{m}=0 \\ \frac{S_{m}+1}{\sqrt{\operatorname{Var}\left(S_{m}\right)}} & \text { if } S_{m}<1\end{cases}
$$

Reports have shown that for $n \geq 25$, the distribution of $S_{m}$ statistic is assumed to be normally distributed. This implies that the mean, $\mu_{s m}=0$, and the variance is defined as:

$$
\operatorname{Var}\left(S_{m}\right)=\frac{n(n-1)(2 n+5)-\sum_{t} t(t-1)(2 t+5)}{18}
$$

$t$ is the number of ties.

Basically, the null hypothesis is rejected, should $Z_{S m}$ yields result less or equal to the $p$-value.

In addition to the aforementioned, the correlation coefficient $r$ (Eq. 4a-4b) was applied to quantify the strength of association between the data distributions. This assesses the observed co-variation, and generally lies in the intervals, $-1 \leq r \leq 1$, where -1 shows negative association, +1 signifies positive relationship, and 0 means no relationship of any kind between the two datasets.

$$
\begin{aligned}
& r=\frac{1}{n-1} \sum_{i=1}^{n}\left[\left(\frac{X_{m}-\bar{X}_{m}}{\sigma_{m}}\right)\left(\frac{X_{o}-\bar{X}_{o}}{\sigma_{o}}\right)\right] \\
& \sigma_{m, o}=\sqrt{\frac{1}{n} \sum_{i=1}^{n}\left(X_{m, o}-\bar{X}_{m, o}\right)^{2}}
\end{aligned}
$$

The refined index of agreement $\left(d_{\text {ref }}\right)$ weights errors and differences, which in turn prevents exaggeration of squared values. It is given as (Willmott et al., 2012):

$$
d_{\text {ref }}=\left\{\begin{array}{l}
1-\frac{\sum_{i=1}^{n}\left|X_{m}-X_{o}\right|}{2 \sum_{i=1}^{n}\left|X_{o}-\bar{X}_{o}\right|}, \text { when } \\
\sum_{i=1}^{n}\left|X_{m}-X_{o}\right| \leq c \sum_{i=1}^{n}\left|X_{o}-\bar{X}_{o}\right| \\
\quad \frac{\sum_{i=1}^{n}\left|X_{m}-X_{o}\right|}{2 \sum_{i=1}^{n}\left|X_{o}-\bar{X}_{o}\right|}-1, \text { when } \\
\sum_{i=1}^{n}\left|X_{m}-X_{o}\right|>2 \sum_{i=1}^{n}\left|X_{o}-\bar{X}_{o}\right|
\end{array}\right.
$$


Consequently, the commonly used error statistics such as; MAE (Eq. 6) and MBE (Eq. 7) were further utilized to quantitatively measure the errors between the observed and the gridded datasets. The MAE presents the magnitude of the mean difference between the measured and interpolated datasets, and varies between 0 and $+\infty$. In any case, 0 value signifies a better score. The MBE demonstrates the degree of under- or overestimation of a model from observed values. It ranges between $-\infty$ and $+\infty$, with 0 value representing a perfect score.

$$
\begin{aligned}
& M A E=\frac{1}{n} \sum_{i=1}^{n}\left|X_{o}-X_{m}\right| \\
& M B E=\frac{1}{n} \sum_{i=1}^{n}\left(X_{m}-X_{o}\right)
\end{aligned}
$$

In Eqs. (4)-(7), $X_{m}$ and $X_{o}$ refer to modelled and observed data; $\bar{X}_{m}$ and $\bar{X}_{o}$ are the mean values of modelled and observed data; $\sigma_{m}$ and $\sigma_{o}$ define the standard deviation of the modelled and observed data; and $\mathrm{n}$ is number of observations.

In $d_{r e f}$ the $95 \%$ confidence interval of each index value was calculated through bootstrap approach as contained in (Pereira et al., 2018).

Finally, it is to be noted that the point-pixel comparison between the datasets were undertaken in this study to avert errors which may arise as a result of gridding of the observed data (Wang et al., 2019).

\subsection{Results and Discussion}

Two selected gridded, gauge-based, minimum and maximum temperature datasets namely; CRU and CPC are validated in this study relative to reference observation data for Upper Benue river basin between 1982 and 2006. These are presented on the annual and monthly timescales as the case may be.

\subsection{Spatial distribution}

The spatial representations of the minimum annual minimum temperature and maximum annual maximum temperature for the 25 years period over Upper Benue river basin are shown in Figure 2 for the reference observational data, CRU and CPC. From the Figure (top row), it is clear that the observed minimum temperature is about $8^{\circ} \mathrm{C}$ over the Cameroon highland $(\mathrm{Gembu}), 11^{\circ} \mathrm{C}$ over the Jos plateau and $10{ }^{\circ} \mathrm{C}$ at the northern fringes of the basin. Consequently, all the datasets captured remarkably well the observed temperature gradient along the varying topography, though with slight overestimation. However, in terms of magnitude, the CPC gives estimates which are closer to the observed values than the CRU dataset. It is to be noted that each of the two main seasons of the year vis-à-vis; dry and rainy seasons has its peculiar low temperatures, which are mainly controlled by (i) the dust-laden wind (the harmattan) driven by the tropical continental (cT) airmass from the Sahara Desert and, (ii) the tropical maritime (mT) airmass from the Atlantic Ocean which is associated with cloudiness and moist convection (Eludoyin et al., 2014; Abatan et al., 2016). While the high elevations of the eastern and north-central highlands are the driving factors for the low temperatures over the Mambila and the Jos plateaus, incidentally, the low temperature in the northern axis of the basin is induced by the harmattan wind, owing to its proximity to the Sahara Desert. Thus, this explains the sole reason why low temperature is recorded in this region. 


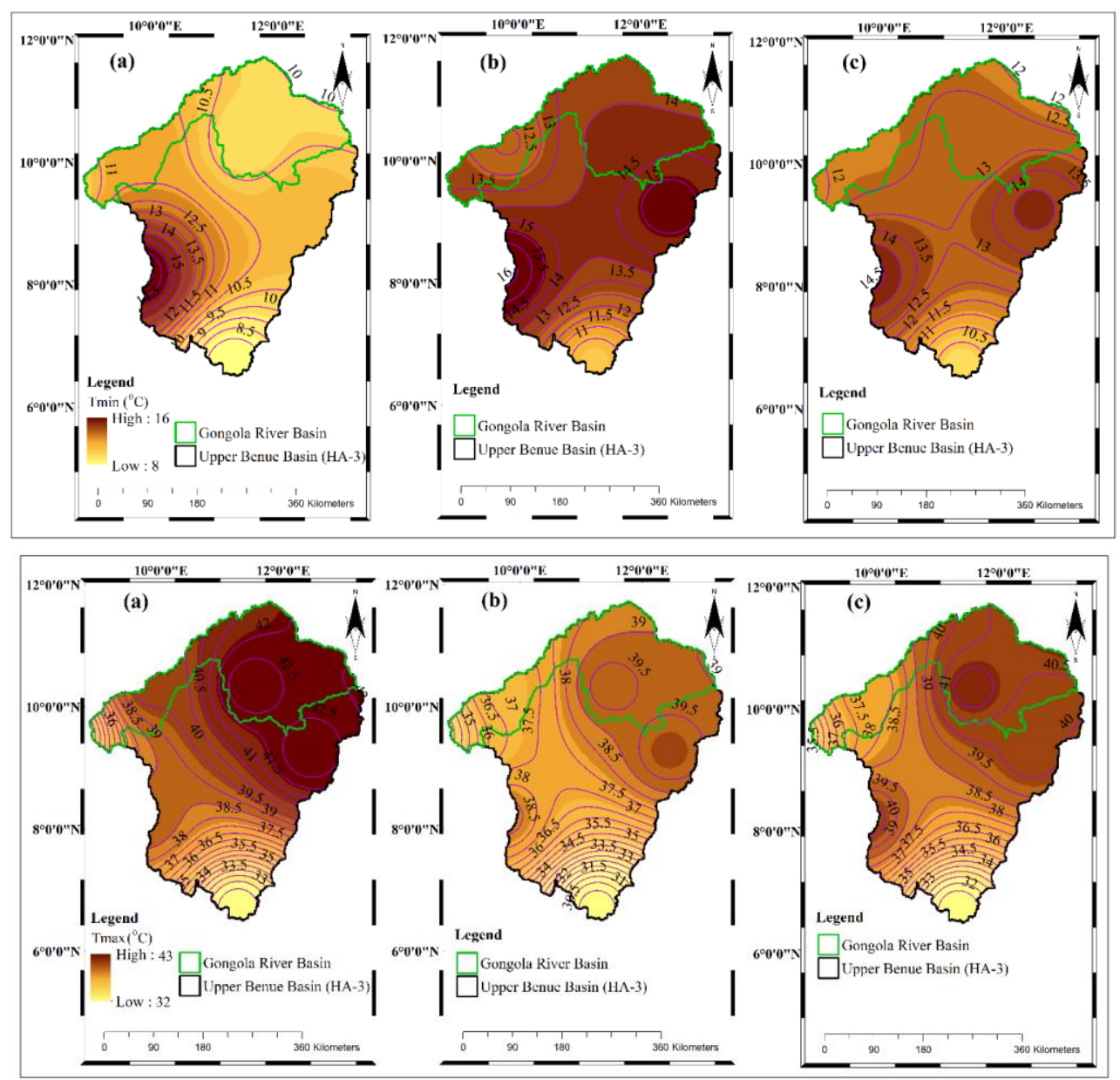

Figure 2: Geographical distribution of temporal temperature datasets covering the period of 19822006 with the top row illustrating the annual minimum temperature, and the bottom row representing the annual maximum temperature for (a) Observed (b) CRU and, (c) CPC.

The observed variations in the maximum annual maximum temperatures (Figure 2, bottom row) over the study domain show a general increasing trend from south to north with marked peak values of 33 , 36 and $42{ }^{\circ} \mathrm{C}$ respectively over Gembu, the Jos plateau and the northern fringes of the basin. The gridded datasets have good representations of the observed trends, though with differing margins. However, the CPC dataset captured reasonably well the observed pattern than the CRU in this regard. The influence of inter-tropical discontinuity (ITD) on the microclimate of the basin is significant, as it controls the spatial variability of climate over Nigeria as a whole, and even the West African subregion. This is a region of trade-wind confluence which generates weak horizontal pressure gradients as a result of contact between the $\mathrm{cT}$ and $\mathrm{mT}$ with consequent, weak wind at the surface. Though, the Saharan heat-low (SHL) dominates the seasonal progression of air temperature over the study domain. In any case, the seasonal evolution of the ITD aligns with the seasonal cycle of the SHL. This accounts for high temperatures being experienced over this region, particularly, during the month of April, as a result of low humidity, occasioned by dry continental air mass associated with SHL.

\subsection{Air temperature anomalies}

The inter-comparison of the anomalies of surface air temperature across the seven meteorological stations over the basin from 1982 to 2006 is shown in Figures 3 and 4 respectively. Figure 3 presents the anomalies for minimum temperature, while Figure 4 indicates the maximum temperature anomalies. Essentially, temperature anomaly measures the inter-annual variability in temperature and allows assessments of the magnitude of deviation of gridded datasets from the observation. Consequently, positive anomalies signify warmer conditions, while negative values depict cooler conditions. The observed anomalies in minimum temperature show increasing trends in all the stations except over Gembu where a decreasing trend was noticed. These conditions are well replicated by the gridded datasets, although, they failed to capture the unique cooling condition over 
Mambila plateau. Interestingly, the gridded datasets represent well the exceptional cooling conditions of 1989 over all the stations, though, with varying magnitudes. Nevertheless, none of the datasets systematically performed best over all the stations. The CRU dataset has improved skill in representing the anomalies over Ibi, Jos and Maiduguri, while CPC dataset better reproduces the anomalies over Bauchi and Yola. In any case, the gridded datasets have worst performance records around Dadin Kowa and Mambila plateau.

The ability of the gridded datasets to skilfully replicate the inter-annual anomalies of the maximum temperature are evaluated similar to the minimum temperature as represented in Figure 4. Here, the CRU dataset better captures the signs and magnitudes of the observed anomalies as compared to the $\mathrm{CPC}$ dataset. However, the $\mathrm{CPC}$ data reproduces the cooling trends in maximum temperature over Mambila plateau to a very large extent. They signify a cooling trend in almost all the stations rather than the warming trend noticeable in the reference observation data, thus, this is alien to the warming trend reported in literature over West Africa including the Upper Benue river basin. It is therefore evident that CRU outperformed CPC in this regard and better represents the observed anomalies.
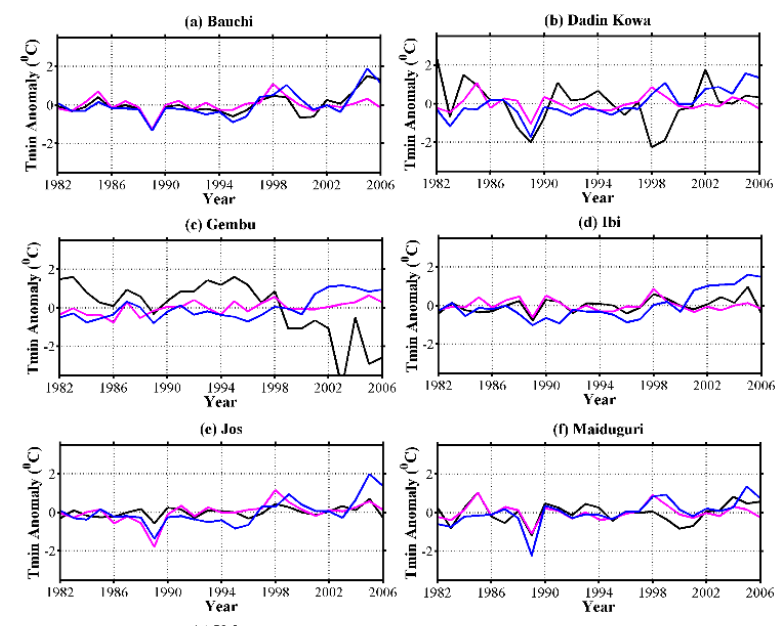

(g) Yola
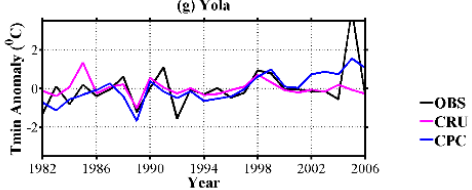

Figure 3: Interannual variability of minimum air temperature anomalies of the reference observation data and CRU and CPC datasets over UBRB between 1982 and 2006
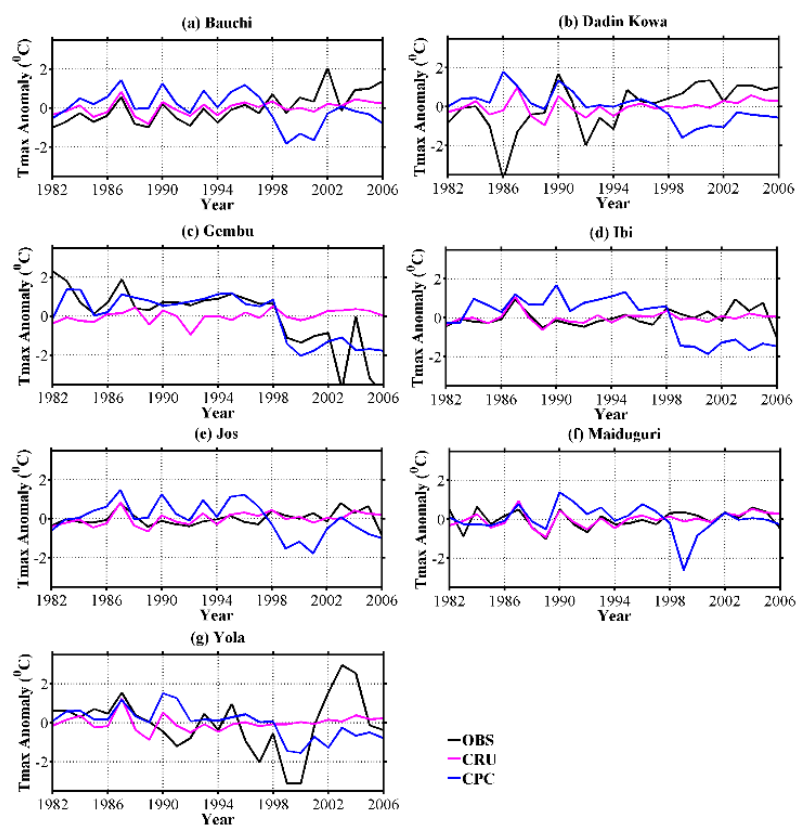

Figure 4: Interannual variability of maximum air temperature anomalies of the reference observation data and CRU and CPC datasets over UBRB between 1982 and 2006 


\subsection{Mean monthly annual cycle of surface air temperature climatology}

The results of the evaluation of annual cycle of mean monthly climatology of air temperature are shown in Figures 5 and 6 respectively, covering a 25 years' period (1982-2006) over the study domain for in-situ measurements and gridded temperature datasets. This presents the capability of the gridded datasets to replicate the seasonal distribution and to demonstrate their skills in capturing the amplitudes and phases of the observed minimum and maximum temperatures. The variations in mean annual cycle of temperature exhibit a bimodal pattern with primary and secondary peak values occurring in the months of April and October respectively everywhere in the basin, except over Mambila plateau where the peak occurred much earlier in February due to early onset of rainy season. This is influenced by the montane climate identified with this region. Consequently, the month of August has a noticeable lowest day and night time temperature values. In any case, the maximum nocturnal temperatures (Figure 5) are $24{ }^{\circ} \mathrm{C}$ in Bauchi, $25^{\circ} \mathrm{C}$ around Dadin Kowa, Ibi and Maiduguri, while Gembu and Jos have unique values of 16 and $18{ }^{\circ} \mathrm{C}$ respectively and $21{ }^{\circ} \mathrm{C}$ in Yola. The highest daytime temperature values (Figure 6) are observed to be in consonant with the night temperatures over the stations, thus, the temperature values at these stations are characterised by diurnal variation with maximum ranging from 28 to $42{ }^{\circ} \mathrm{C}$.

These observed features in seasonal temperature variations everywhere in the basin are well replicated to a large extent by the gridded datasets, though with noticeable over- and underestimations. It is worthy of note that the gridded datasets grossly overestimate the observed pattern over Gembu and Yola which appear to be more in CPC dataset, suggesting CRU dataset to be more outstanding in this regard.
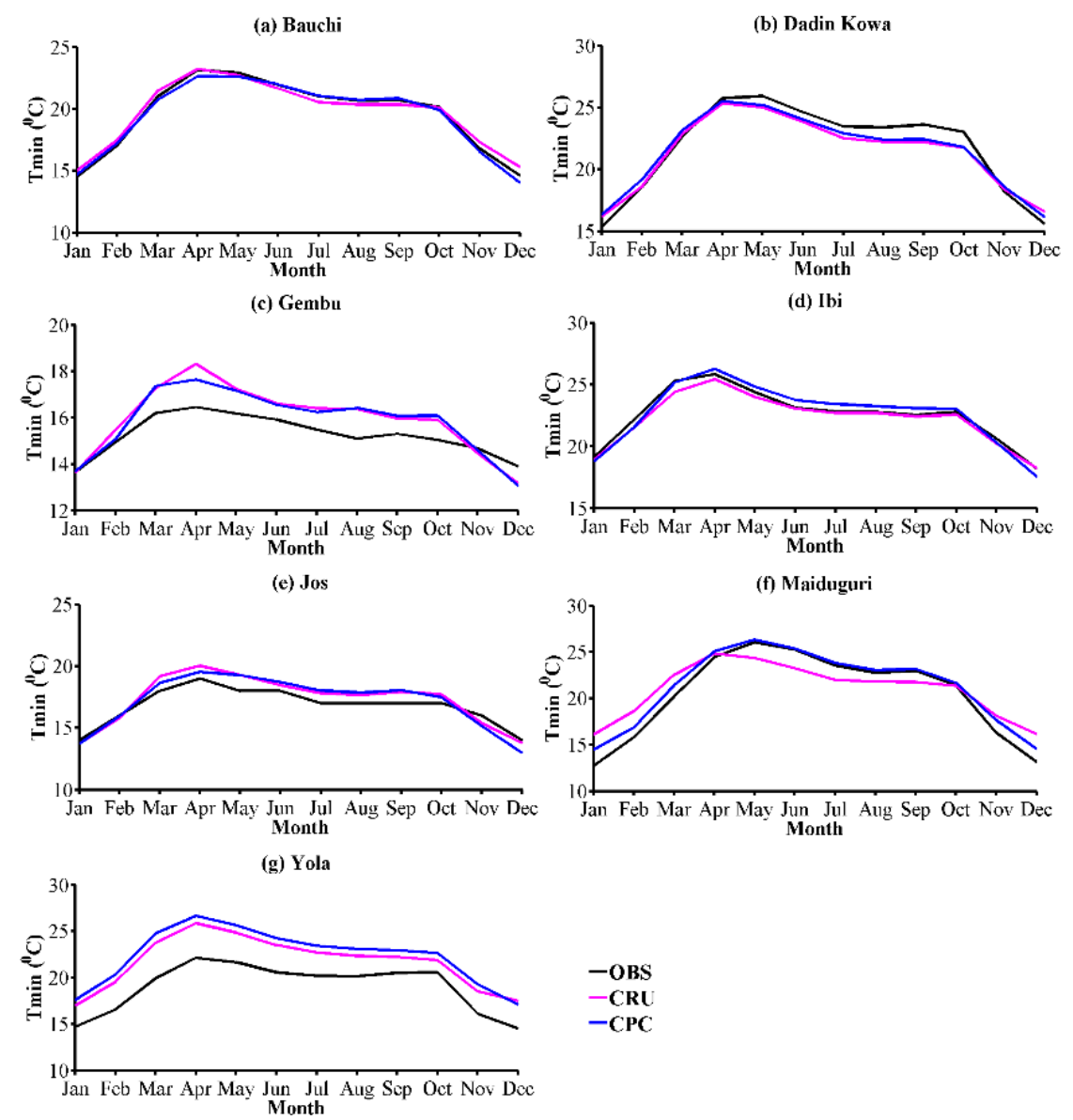

$$
\begin{aligned}
& -\mathrm{OBS} \\
& -\mathrm{CRU} \\
& -\mathrm{CPC}
\end{aligned}
$$

Figure 5: Mean monthly annual cycle of minimum temperature between 1982 and 2006 

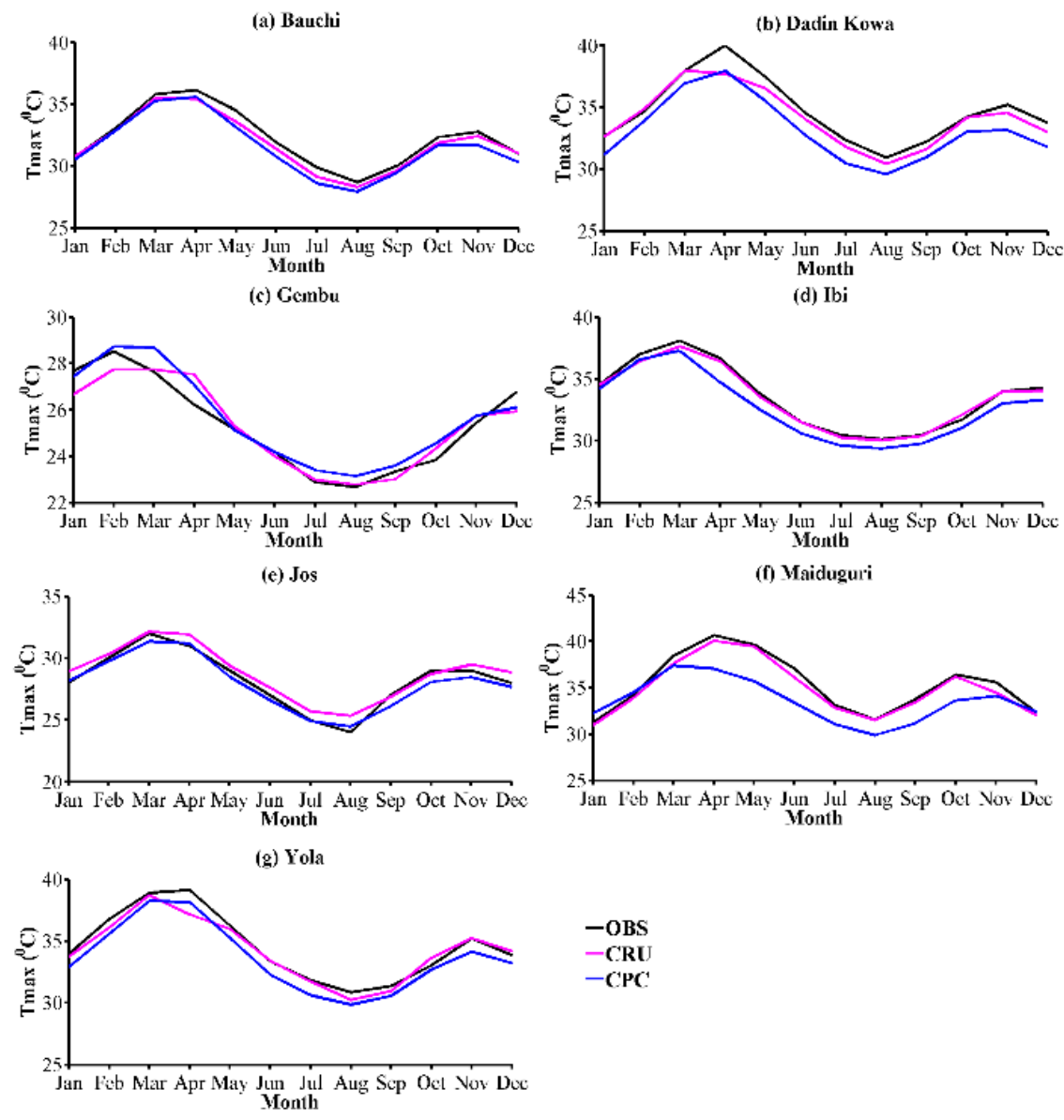

$$
\begin{aligned}
& -\mathrm{OBS} \\
& -\mathrm{CRU} \\
& -\mathrm{CPC}
\end{aligned}
$$

Figure 6: Mean monthly annual cycle of maximum temperature between 1982 and 2006

\subsection{Analysis of PDFs for minimum and maximum temperatures}

The capabilities of the spatially interpolated temperature datasets to measure closely the distributions of the observed minimum and maximum temperature data over the basin was evaluated using PDF metric along with Perkin's skill score. Figures 7 and 8 show comparison of observed and spatially interpolated PDFs for minimum and maximum temperatures respectively; while, Figures 9(a) and (b) indicate their corresponding PDF-based skill scores. The shapes of the gridded data's PDFs for both minimum and maximum temperatures measured closely the shape of the observed PDF, similar to the findings reported by Perkins et al. (2007), Fu et al. (2013), and Anandhi et al. (2019). Although, the deviations of the gridded datasets from observed data are substantial in Gembu and Yola for minimum temperature, but have improved skill in replicating the observed maximum temperature. The CPC PDFs closely match the observed PDFs over Bauchi and Maiduguri for minimum temperature, while the CRU produced the best replica over Bauchi, Ibi and Jos plateau for maximum temperature.

The skill score in Figure 9(a) and (b) reveal the strength and weakness of the gridded datasets in representing the observed PDFs. This generally varies from 0.6 to 0.9 for minimum temperature, while the range in maximum temperature is between 0.5 and 0.9 . The results from the skill score agree with those obtained from the PDFs. Apparently, the CPC data skill scores are higher for minimum temperature, while the CRU shows better performance for maximum temperature. In any case, the CPC dataset is found to have best skill score and therefore appears to be most agreeable with the reference observational data, hence it is considered to be most outstanding in representing the distribution of the observed temperature over the entire study domain. 

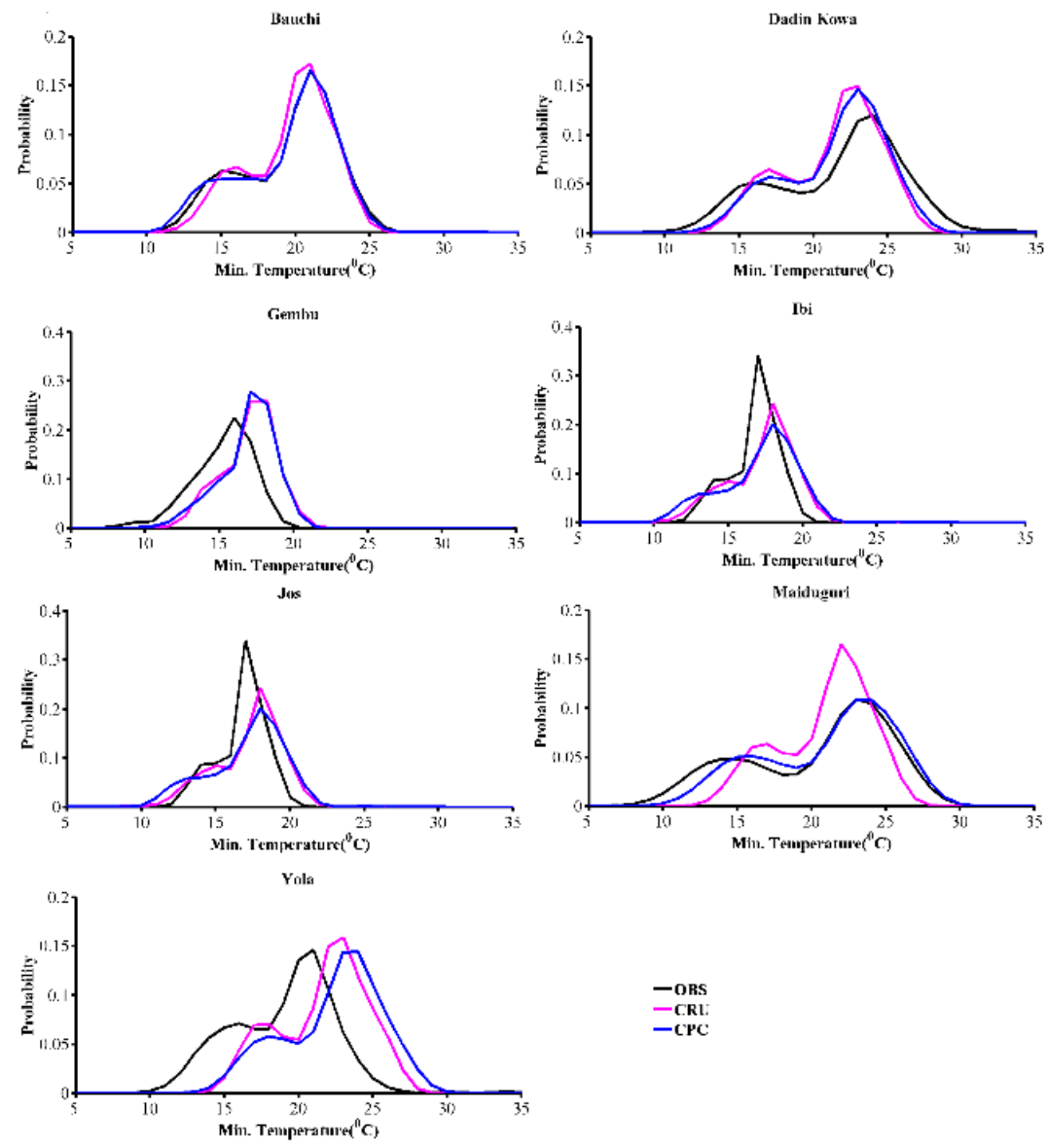

$$
\begin{aligned}
& \text {-ORS } \\
& \text { - CRL: } \\
& \text {-CPC }
\end{aligned}
$$

Figure 7: Probability density function for observed and gridded minimum temperature dataset
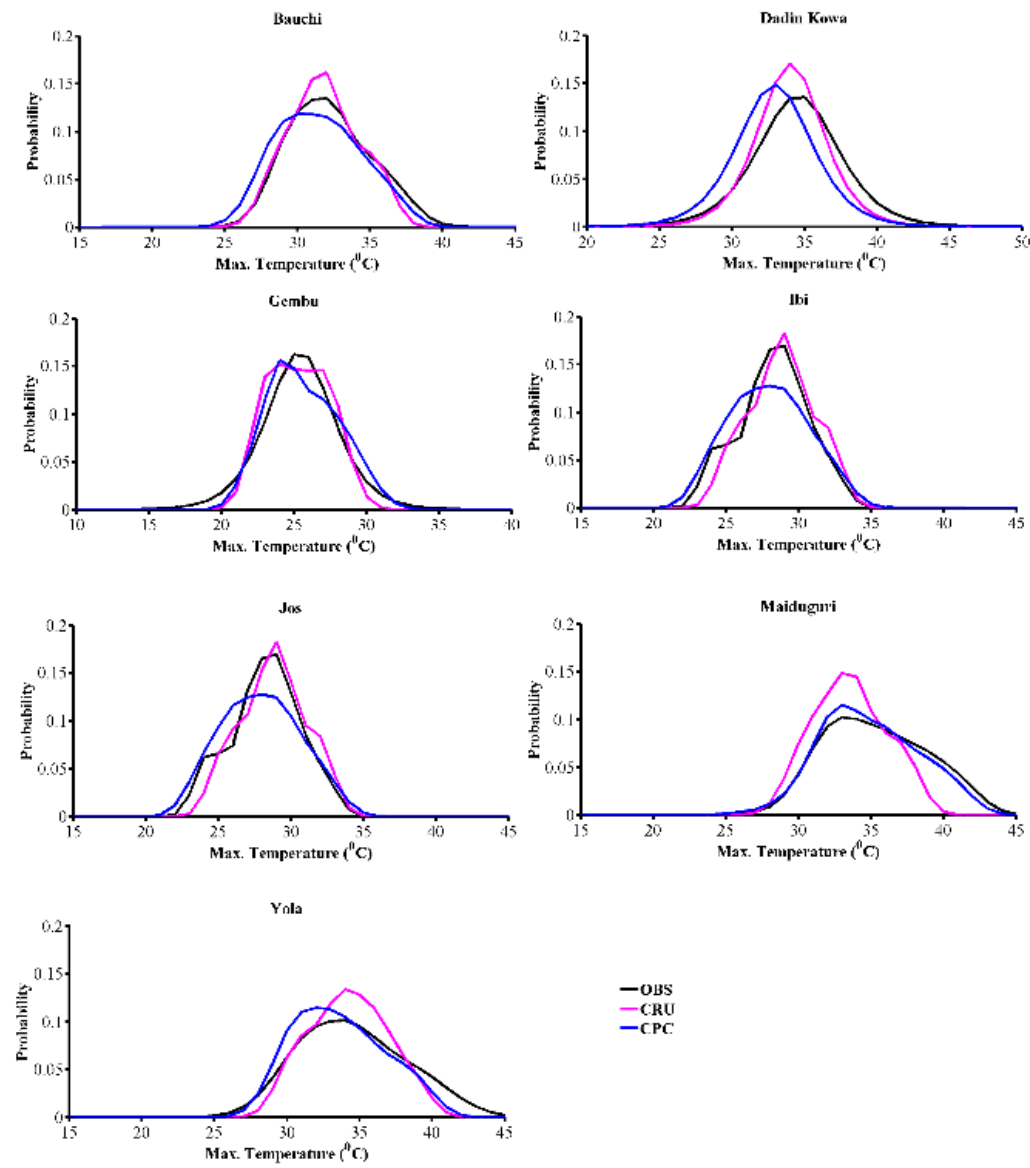

-OBS
-CRU
$-\mathrm{CPC}$

Figure 8: Probability density function for observed and gridded maximum temperature dataset 
(a)

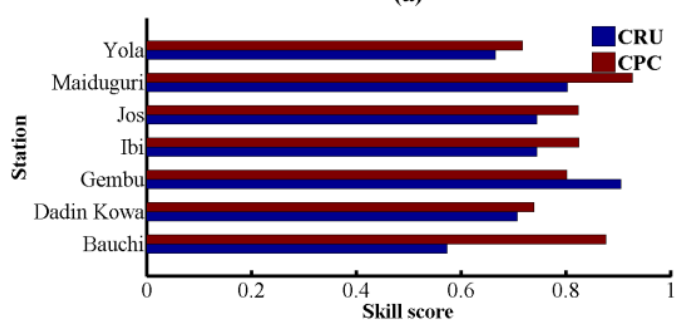

(b)

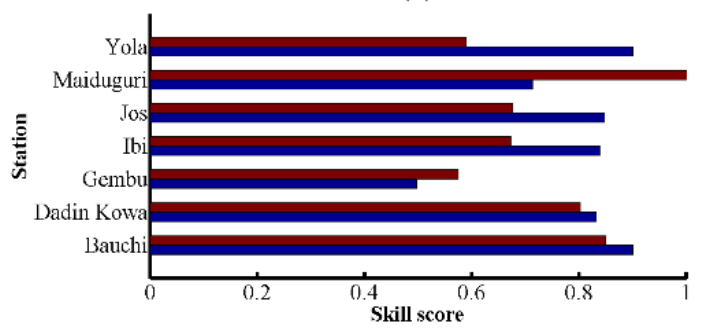

Figure 9: PDF- based skill score for (a) minimum temperature (b) maximum temperature

\subsection{Analysis of Statistical Indices}

In this section, the results from different statistical methods applied to the monthly minimum and maximum temperature are presented for the seven weather stations in Upper Benue river basin to further understand the performance of the gridded datasets. Figures 10 (a) and (b) present the MBE for the minimum and maximum temperature respectively; while the MAE are shown in Figures 11 (a) and (b) indicating the quantitative measure of the dataset. Likewise, the root mean square error, RMSE, coefficient of correlation, $r$ and, refined index of agreement, $d_{r e f}$ for the datasets are presented in Table 2 and 3. MBE indicates the degree of over- or under-prediction of observation; while MAE and RMSE are pointers to the overall performance of the gridded datasets; a high MAE signifies a poor replica of observation, while a low MAE depicts good performance. This is also true for RMSE. The $r$ and $d_{r e f}$ measure the degree of correspondence between the modelled and observed data. The use of $d_{\text {ref }}$ for the evaluation in conjunction with $r$ was primarily to strengthen the outputs, since the results from $d_{r e f}$ are not influenced by the presence of outliers in datasets. In the main, the two datasets are noted to have similar biases, though with varying magnitudes: positive bias for the minimum temperature, while the maximum temperature has negative bias, with exception of few stations. On the whole, the warm bias is most prevalent over Yola than other stations suggesting overestimation of the observed minimum temperature. The magnitudes are more in CPC than the CRU datasets. Conversely, the CRU dataset grossly underestimates the observed maximum temperature in Maiduguri station, but nevertheless, the underestimations are more in CPC dataset than in CRU, suggesting a better representation of the observed temperature values.

(a)

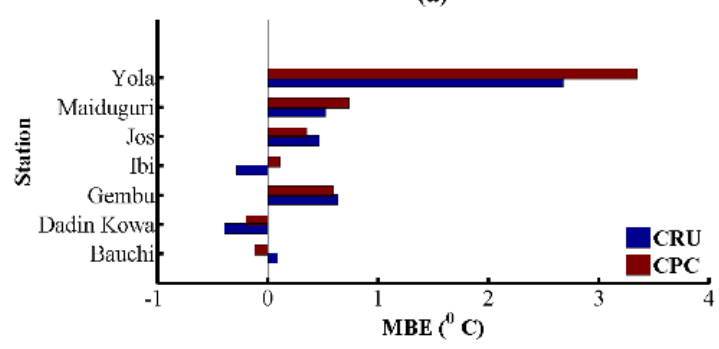

(b)

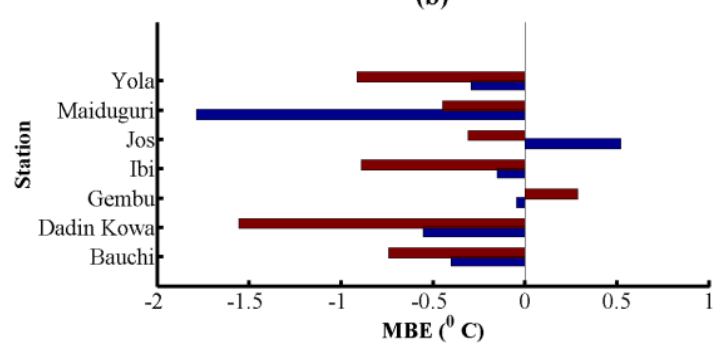

Figure 10: Mean bias error for (a) minimum temperature (b) maximum temperature

Further assessment using MAE and RSME indices demonstrate similar magnitudes of errors to those obtained from MBE between the reference ground observation dataset and the gauge-based data. Consequently, the CRU dataset records the lowest MAE and RMSE in most of the stations with the exceptions of Bauchi, Gembu and Maiduguri for both minimum and maximum temperature, though with narrow margins. However, Yola weather station depicts the highest MAE and RMSE and turnout to be the worst of all stations for both datasets. Nevertheless, the CRU dataset appears to be substantially better than the CPC owing its low error statistics. 
(a)

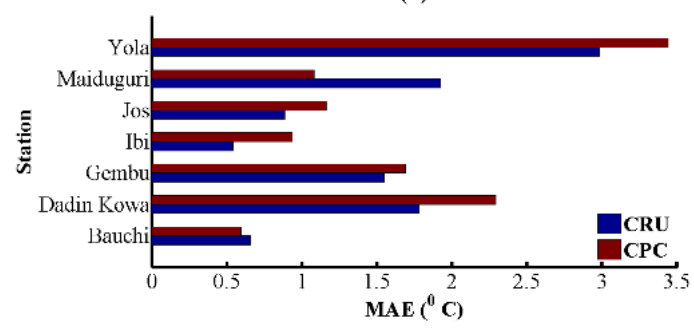

(b)

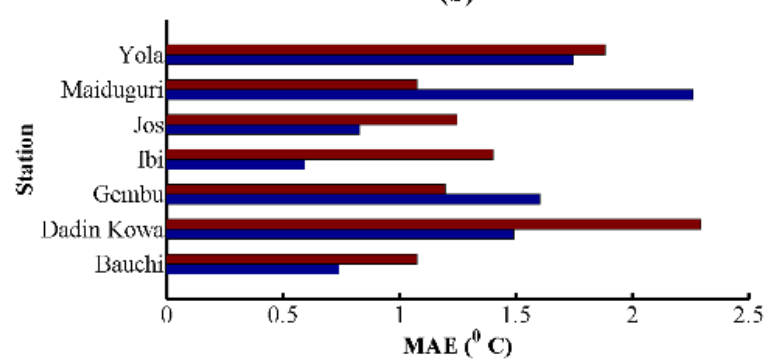

Figure 11: Mean absolute error for (a) minimum temperature (b) maximum temperature

The $d_{\text {ref }}$ proposed by Willmott et al. (2012) and demonstrated by Pereira et al. (2018) was used to test the level of agreement of the datasets relative to the reference observations over the study domain. The results obtained from the $d_{r e f}$ are similar to those from $r$. However, the range of values obtained using $d_{\text {ref }}$ are generally lower but yet credible enough to reveal the accuracy of the datasets. For instance, the CRU and CPC datasets have $r$ values that vary from 0.72 to 0.97 for minimum temperature, and 0.61 to 0.92 for maximum temperature. Correspondingly, the $d_{r e f}$ generally range between 0.50 and 0.89 for the gridded datasets for both minimum and maximum temperatures. However, Yola station recorded exceptionally low $d_{\text {ref }}$ of 0.46 and 0.37 respectively for CRU and CPC. This range of values concurs with those obtained from $r$ and therefore reveals the strengths of the temperature products across the basin. Based on level of agreement with the ground reference observations in terms of correspondence and low error value, CRU was found to be more reliable than CPC.

The ability of the monthly gridded temperature datasets to measure closely the observed trends was evaluated over Upper Benue river basin using Mann-Kendal rank statistics, $\tau$. These are shown in Tables 2 and 3 for the minimum and maximum temperatures respectively. During 1982-2006, the observed temperatures in the basin depict statistically significant and nonsignificant warming trends at $5 \%$ significance level over the stations. Nevertheless, over a significant cooling trend were recorded for both minimum and maximum temperatures over Gembu. Separate reports indicating decreasing trend in temperature over the montane climate zones in Nigeria are substantially available in literature (e.g. Akinsanola and Ogunjobi, 2014; Abatan et al., 2016; Yusuf et al., 2017). However, Dadin Kowa and Yola stations show decreasing trends for minimum and maximum temperatures respectively. The warming trend is well replicated over most stations by the datasets. Nevertheless, CRU failed to capture the warming trend over Ibi, Maiduguri and Yola for minimum temperature; while, CPC lacks skill in depicting the warming trend over majority of the stations for maximum temperature. To a large extent, the degrees of warming and cooling trends are in some cases over- and under-predicted by the datasets. The findings on warming trend of temperature data over the study domain are well supported by earlier studies (e.g. Eludoyin et al., 2014; Abatan et al., 2016; Ilori and Ajayi, 2020) who separately reported statistically significant increasing trend in both minimum and maximum temperature over most part of Nigeria.

Table 2: Mann-Kendall rank statistic, $\tau$, coefficient of correlation, $r$, refined index of agreement, $d_{\text {ref }}$ and, root mean square error, RMSE for minimum temperature $\left({ }^{\circ} \mathrm{C}\right)$.

\begin{tabular}{|c|c|c|c|c|c|c|c|c|c|}
\hline \multirow{2}{*}{ Station } & OBS & CRU & $\mathrm{CPC}$ & CRU & CPC & CRU & $\mathrm{CPC}$ & CRU & CPC \\
\hline & \multicolumn{3}{|c|}{$\tau$} & \multicolumn{2}{|c|}{$\mathbf{r}$} & \multicolumn{2}{|c|}{$d_{\text {ref }}$} & \multicolumn{2}{|c|}{ RMSE } \\
\hline Bauchi & $0.220 * *$ & $0.073 * *$ & $0.233 * *$ & 0.959 & 0.964 & 0.874 & 0.886 & 0.917 & 0.858 \\
\hline Dadin Kowa & $-0.084 * *$ & $0.007 * *$ & 0.500 & 0.832 & 0.683 & 0.749 & 0.677 & 2.418 & 3.126 \\
\hline Gembu & $-0.450 * *$ & 0.387 & 0.433 & 0.721 & 0.774 & 0.517 & 0.621 & 2.213 & 2.450 \\
\hline Ibi & $0.220 * *$ & $-0.040 * *$ & $0.367 * *$ & 0.950 & 0.901 & 0.846 & 0.733 & 0.787 & 1.227 \\
\hline Jos & $0.067 * *$ & $0.048 * *$ & 0.113 & 0.912 & 0.843 & 0.644 & 0.533 & 1.080 & 1.447 \\
\hline Maiduguri & $0.007 * *$ & $-0.017 * *$ & $0.064 * *$ & 0.920 & 0.969 & 0.765 & 0.868 & 2.313 & 1.417 \\
\hline Yola & $0.070 * *$ & $-0.023 * *$ & 0.121 & 0.746 & 0.719 & 0.458 & 0.374 & 3.506 & 3.991 \\
\hline
\end{tabular}


Table 3: Mann-Kendall rank statistic, $\tau$, coefficient of correlation, $r$, refined index of agreement, $d_{\text {ref }}$ and, root mean square error, RMSE for maximum temperature $\left({ }^{\circ} \mathrm{C}\right)$.

\begin{tabular}{|c|c|c|c|c|c|c|c|c|c|}
\hline \multirow[b]{2}{*}{ Station } & OBS & CRU & CPC & CRU & $\mathrm{CPC}$ & CRU & CPC & CRU & $\mathrm{CPC}$ \\
\hline & \multicolumn{3}{|c|}{$\tau$} & \multicolumn{2}{|c|}{$\mathbf{r}$} & \multicolumn{2}{|c|}{$\mathbf{d}_{\text {ref }}$} & \multicolumn{2}{|c|}{ RMSE } \\
\hline Bauchi & 0.533 & 0.327 & $-0.253 * *$ & 0.911 & 0.838 & 0.832 & 0.756 & 1.196 & 1.734 \\
\hline Dadin Kowa & 0.487 & 0.360 & -0.507 & 0.809 & 0.710 & 0.703 & 0.544 & 1.976 & 2.810 \\
\hline Gembu & -0.494 & $0.280 * *$ & -0.440 & 0.607 & 0.789 & 0.624 & 0.717 & 2.156 & 1.690 \\
\hline Ibi & $0.019 * *$ & $0.004 * *$ & -0.176 & 0.961 & 0.840 & 0.466 & 0.707 & 0.784 & 1.840 \\
\hline Jos & $0.019 * *$ & $0.037 * *$ & -0.107 & 0.919 & 0.804 & 0.777 & 0.665 & 1.052 & 1.603 \\
\hline Maiduguri & $0.005 * *$ & $0.021 * *$ & $-0.039 * *$ & 0.806 & 0.907 & 0.601 & 0.810 & 2.692 & 1.503 \\
\hline Yola & $-0.043^{* *}$ & $0.004 * *$ & -0.128 & 0.757 & 0.763 & 0.693 & 0.669 & 2.283 & 2.441 \\
\hline
\end{tabular}

\subsection{Conclusions}

Adequate meteorological variables such as; temperature datasets needed for impact models are lacking over Upper Benue river basin due to inadequate spatiotemporal continuity and distributions of gauging stations as well as limited and restricted accessibility. Accordingly, we present in this study the inter-comparison of two global, gauge-based gridded temperature datasets (CRU, CPC) with ground-based reference observations to assess their skills in representing the present-day observed temperature climatology. Results from spatial distributions of both minimum and maximum temperatures show the gridded datasets to represent reasonably well the observed patterns. There are markedly low temperatures over the Jos plateau and the Cameroon highland in the western and southern peripheries of the basin due to high altitudes. Temperature increases exponentially as one move towards the northern fringes of the basin. However, an exceptionally low temperature around the northern axis during the harmattan period is well documented owing to its proximity to Sahara Desert. By the way, the CPC dataset showed improved skill in replicating these observed features.

The interannual variability in both minimum and maximum temperatures show positive anomalies, which signify warming trends in almost all the stations; except over Gembu, where a cooling trend was noticed. The gridded datasets measured closely these observed conditions. However, CRU datasets are noted to outperform the CPC data in this regard. Also, the annual cycle of mean monthly temperature exhibits a bimodal pattern, with primary and secondary peaks occurring in the months of April and October everywhere in the basin except over Gembu. In any case, the nocturnal temperature variations range from 13 to $25{ }^{\circ} \mathrm{C}$, while the diurnal temperature varies between 23 and $42{ }^{\circ} \mathrm{C}$. Overall, temperatures are lower over the Jos plateau and Cameroon highland with Maiduguri recording the highest maximum temperature. Interestingly, the gridded temperature products show good skills in capturing the observed amplitudes and phases, though with varying margins.

Results from PDF analysis reveal the shapes of the PDFs for the spatial interpolated datasets to capture remarkably well those of the observed PDFs everywhere in the basin, although, substantial difference exists over Gembu and Yola in minimum temperature. In any case, the dispersity was noted to be higher in CPC than in CRU dataset. These findings were further corroborated by Perkin's skill scores for the PDFs which indicate good performance of the gridded datasets in the range of 0.6 to 0.9 and 0.5 to 0.9 for minimum and maximum temperatures respectively.

Further assessments indicate CRU to be substantial in this study as compared to CPC owing to its lowest error magnitudes and higher degrees of pattern correspondence using statistical indicators as MAE, MBE, RMSE, $r$ and $d_{r e f}$. Also, results from Mann-Kendall statistics suggest significant warming trend for both minimum and maximum temperatures, except over the Cameroon highland where a significant cooling trend was obvious. The CRU datasets reproduced these observed trends with some degrees of accuracies, whereas CPC was dubious in replicating the observed warming trends for maximum temperature over the entire study domain. In spite of the improved performance of CRU over CPC in most stations, CPC was as well noted to outperform CRU in some stations. Based on improved performance of CRU datasets over the study site, it is therefore deemed suitable for impact models. 


\section{Acknowledgements}

The financial support to the first author by the Federal Government of Nigeria through Tertiary Education Trust Fund for Academic Staff Training and Development is greatly acknowledged. The authors are grateful to the services that have operated the CRU and CPC.

\section{References}

Abatan, A.A., Abiodun, B.J., Lawal, K.A. and Gutowski, W.J. (2016). Trends in Extreme Temperature over Nigeria from Percentile-based Threshold Indices. Int. J. Climatol. 36(6), pp. 25272540.

Adebayo, A.A. and Yahya, A.S. (2015). Assessment of Climate Change in the Savannah Sugar Project Area, Adamawa State, Nigeria. $15^{\text {th }}$ International Academic Conference. Rome, pp. 19-28.

Adeniyi, M.O. and Dilau, K.A. (2015). Seasonal Prediction of Precipitation over Nigeria. J. Sci. Tech (Ghana). 35(1), pp. 103-113.

Agyekum, J., Annor, T., Lamptey, B., Quansah, E. and Agyeman, R.Y.K. (2018). Evaluation of CMIP5 Global Climate Models over the Volta Basin: Precipitation. Adv Meteorol. 2018, pp. 1-24.

Akande, A., Costa, A.C., Mateu, J. and Henriques, R. (2017). Geospatial Analysis of Extreme Weather Events in Nigeria (1985-2015) using Self-organizing Maps. Adv. Meteorol. 2017, pp. 1-11.

Akinsanola, A.A., Ajayi, V.O., Adejare, A.T., Adeyeri, O.E., Gbode, I.E., Ogunjobi, K.O., Nikulin, G. and Abolude, A.T. (2017). Evaluation of Rainfall Simulations over West Africa in Dynamically Downscaled CMIP5 Global Circulation Models. Theor Appl Climatol. 132(1-2), pp. 437-450.

Akinsanola, A.A. and Ogunjobi, K.O. (2014). Analysis of Rainfall and Temperature Variability Over Nigeria. Global Journal of Human-Social Science: B Geography, Geo-Sciences, Environmental Disaster Management, 13(3), pp. 1-19.

Akinsanola, A.A., Ogunjobi, K.O., Ajayi, V.O., Adefisan, E.A., Omotosho, J.A. and Sanogo, S. (2016). Comparison of Five Gridded Precipitation Products at Climatological Scales over West Africa. Meteorol Atmos Phys. 129(6), pp. 669-689.

Anandhi, A., Pierson, D.C. and Frei, A. (2019). Evaluation of Climate Model Performance for Water Supply Studies: Case Study for New York City. J. Water Resour. Plann. Manage. 145(8), pp. 33023311.

Burton, C., Rifai, S. and Malhi, Y. (2018). Inter-comparison and Assessment of Gridded Climate Products over Tropical Forests during the 2015/2016 El Nino. Philos Trans R Soc Lond B Biol Sci. 373(1760), pp. 1-10.

Chen, U.K.O.W., Chineke, C. and Nwofor, O. (2014). Comparative Analysis of Gridded Datasets and Gauge Measurements of Rainfall in the Niger Delta Region. Res. J. Environ. Sci. 88(7), pp. 373-390.

Collins, J.M. (2011). Temperature Variability over Africa. J. Clim. 24(14), pp. 3649-3666.

Daly, C. (2006). Guidelines for Assessing the Suitability of Spatial Climate Data sets. Int. J. Climatol. 26(6), pp. 707-721.

Eludoyin, O.M., Adelekan, I.O., Webster, R. and Eludoyin, A.O. (2014). Air Temperature, Relative Humidity, Climate Regionalization and Thermal Comfort of Nigeria. Int. J. Climatol. 34(6), pp. 20002018.

Federal Government of Nigeria (2012). Annual Abstract of Statistics. National Bureau of Statistics Abuja: www.nigerianstat.gov.ng. 
Fu, G., Liu, Z., Charles, S.P., Xu, Z. and Yao, Z. (2013). A Score-based Method for Assessing the Performance of GCMs: A Case Study of Southeastern Australia. J. Geophys. Res. Atmos. 118(10), pp. 4154-4167.

Harris, I., Jones, P.D., Osborn, T.J. and Lister, D.H. (2014). Updated High-resolution Grids of Monthly Climatic Observations - the CRU TS3.10 Dataset. Int. J. Climatol. 34(3), pp. 623-642.

Hassan, I., Kalin, R.M., White, C.J. and Aladejana, J.A. (2020). Evaluation of Daily Gridded Meteorological Datasets over the Niger Delta Region of Nigeria and Implication to Water Resources Management. Atmos Clim Sci. 10(01), pp. 21-39.

Hooker, J., Duveiller, G. and Cescatti, A. (2018). A Global Dataset of Air Temperature Derived from Satellite Remote Sensing and Weather Stations. Sci Data. 5, pp. 1-11.

Ilori, O.W. and Ajayi, V.O. (2020). Change Detection and Trend Analysis of Future Temperature and Rainfall over West Africa. Earth Syst. Environ. 4(3), pp. 493-512.

Japan International Cooperation Agency (JICA) (2014). National Water Rresources Master Plan 2013. Federal Ministry of Water Resources (ed.) Volume 4. Abuja: Federal Government of Nigeria.

Jia, K., Ruan, Y., Yang, Y. and Zhang, C. (2019). Assessing the Performance of CMIP5 Global Climate Models for Simulating Future Precipitation Change in the Tibetan Plateau. Water. 11(9), pp. 1771.

Kabela, E.D. and Carbone, G.J. (2015). NARCCAP Model Skill and Bias for the Southeast United States. Am. J. Clim. Change. 04(01), pp. 94-114.

Kanda, N., Negi, H.S., Rishi, M.S. and Kumar, A. (2020). Performance of Various Gridded Temperature and Precipitation Datasets over Northwest Himalayan Region. Environ. Res. Commun. 2(8), pp. 1-20.

Maxino, C.C., Mcavaney, B.J., Pitman, A.J. and Perkins, S.E. (2008). Ranking the AR4 Climate Models over the Murray-Darling Basin using Simulated Maximum Temperature, Minimum Temperature and Precipitation. Int. J. Climatol. 28, pp. 1097-1112.

Mondal, A., Lakshmi, V. and Hashemi, H. (2018). Intercomparison of Trend Analysis of Multisatellite Monthly Precipitation Products and Gauge Measurements for River Basins of India. $J$. Hydrol. 565, pp. 779-790.

Nashwan, M.S., Shahid, S. and Chung, E.S. (2019). Development of High-resolution Daily Gridded Temperature Datasets for the Central North Region of Egypt. Sci Data. 6(1), pp. 1-13.

New, M., Hulme, M. and Jones, P. (1999). Representing Twentieth-Century Space-Time Climate Variability. Part I: Development of a 1961-90 Mean Monthly Terrestrial Climatology. J. Clim. . 12, pp. 829-856.

New, M., Hulme, M. and Jones, P. (2000). Representing Twentieth-Century Space-Time Climate Variability. Part II: Development of 1901-96 Monthly Grids of Terrestrial Surface Climate. J. Clim. 13, pp. 2217-2238.

NOAA/OAR/ESRL PSL CPC Global Unified Precipitation data. From their Website at https://PSL.NOAA.Gov/. Boulder, Colorado, USA.

Pereira, H.R., Meschiatti, M.C., Pires, R.C.D.M. and Blain, G.C. (2018). On the Performance of Three Indices of Agreement: An Easy-to-use R-code for Calculating the Willmott Indices. Bragantia. 77(2), pp. 394-403. 
Perkins, S.E., Pitman, A.J., Holbrook, N.J. and Mcaneney, J. (2007). Evaluation of the AR4 Climate Models' Simulated Daily Maximum Temperature, Minimum Temperature, and Precipitation over Australia Using Probability Density Functions. J. Clim. 20, pp. 4356-4376.

Piyoosh, A.K. and Ghosh, S.K. (2016). A Comparative Assessment of Temperature Data from Different Sources for Dehradun, Uttarakhand, India. J. Meteor. Res. 30(6), pp. 1019-1032.

Shiru, M.S., Shahid, S., Alias, N. and Chung, E.-S. (2018). Trend Analysis of Droughts during Crop Growing Seasons of Nigeria. Sustainability. 10(871), pp. 1-13.

Sun, Q., Miao, C., Duan, Q., Ashouri, H., Sorooshian, S. and Hsu, K.-L. (2018). A Review of Global Precipitation Data Sets: Data Sources, Estimation, and Intercomparisons. Rev Geophys. 56, pp. 79107.

Tanarhte, M., Hadjinicolaou, P. and Lelieveld, J. (2012). Intercomparison of temperature and precipitation data sets based on observations in the Mediterranean and the Middle East. J. Geophy Res. Atmos. 117(D12), pp. 1-24.

Tang, G., Ding, Y., Wang, S., Ren, G., Liu, H. and Zhang, L. (2010). Comparative Analysis of China Surface Air Temperature Series for the Past 100 Years. Adv. Clim. Chang. Res. 1(1), pp. 11-19.

Vaghefi, S.A., Abbaspour, N., Kamali, B. and Abbaspour, K.C. (2017). A Toolkit for Climate Change Analysis and Pattern Recognition for Extreme Weather Conditions-Case Study: California-Baja California Peninsula. Environ. Model. Softw. 96, pp. 181-198.

Wang, G., Zhang, X. and Zhang, S. (2019). Performance of Three Reanalysis Precipitation Datasets over the Qinling-Daba Mountains, Eastern Fringe of Tibetan Plateau, China. Adv. Meteorol. 2019, pp.1-16.

Weli, V.E., Nwagbara, M.O. and Ozabor, F. (2017). The Minimum and Maximum Temperature Forecast Using Statistical Downscaling Techniques for Port-Harcourt Metropolis, Nigeria. Atmo. Clim. Sci. 07(04), pp. 424-435.

Willmott, C.J., Robeson, S.M. and Matsuura, K. (2012). A Refined Index of Model Performance. Int. J. Climatol. 32(13), pp. 2088-2094.

Yusuf, N., Okoh, D., Musa, I., Adedoja, S. and Said, R. (2017). A Study of the Surface Air Temperature Variations in Nigeria. Open Atmospheric Sci. J. 11(1), pp. 54-70. 